\title{
COMPARAÇÃO DE HÁBITOS DE BEM ESTAR VOCAL ENTRE CANTORES LÍRICOS E POPULARES
}

\section{A comparison between vocal habits of lyric and popular singers}

\author{
Ana Paula Dassie-Leite ${ }^{(1)}$, André de Campos Duprat ${ }^{(2)}$, Roberta Busch ${ }^{(3)}$
}

\begin{abstract}
RESUMO
Objetivo: comparar hábitos de bem estar vocal entre cantores líricos e populares. Métodos: foi realizado um trabalho exploratório descritivo, com a participação de 30 cantores líricos e 30 populares, estudantes da Universidade Livre de Música. Todos responderam um questionário com 13 questões objetivas sobre hábitos vocais e utilização profissional da voz. Os dados foram tabulados e analisados estatisticamente Resultados: cantores líricos e populares têm hábitos semelhantes de alimentação, tabagismo, etilismo e uso de drogas recreacionais. Cantores populares têm menos horas de sono/ repouso ao dia, sendo esta uma diferença estatisticamente significante. Este grupo também se diferenciou dos cantores líricos por terem, em sua maioria, outro trabalho com a utilização profissional da voz falada. Também foi estatisticamente significante a maior carga horária no uso da voz cantada em líricos, bem como o maior uso de recursos considerados mitos para melhorar a voz. Cantores populares conhecem menos o trabalho fonoaudiológico junto aos profissionais da voz. Os cantores líricos aquecem a voz com maior frequência em relação aos populares, embora este segundo grupo, tenha demonstrado que este hábito tem sido adquirido. Tanto cantores líricos quanto populares não desaquecem a voz sistematicamente, depois da atividade profissional. Conclusão: Cantores líricos e populares com formação musical específica têm, em geral, hábitos de bem estar vocal semelhantes e diferenciam-se principalmente em relação à carga horária de trabalho semanal, à utilização de mitos na tentativa de melhorar a voz, ao conhecimento sobre o trabalho fonoaudiológico e à prática de aquecimento e desaquecimento vocal.
\end{abstract}

DESCRITORES: Voz; Distúrbios da Voz; Hábitos; Música

\section{INTRODUÇÃO}

Cantores de diferentes estilos musicais estão cada vez mais interessados em conhecer suas

(1) Fonoaudióloga. Professora Assistente A do Departamento de Fonoaudiologia da Universidade Estadual do Centro Oeste/UNICENTRO, Irati, PR, Brasil. Mestre em Saúde da Criança e do Adolescente pela Universidade Estadual de Campinas/UNICAMP.

(2) Médico otorrinolaringologista. Professor da Faculdade de Ciências Médicas da Santa Casa de São Paulo, São Paulo, SP, Brasil. Doutor pelo Departamento de Otorrinolaringologia da Faculdade de Ciências Médicas da Santa Casa de São Paulo.

(3) Fonoaudióloga. Coordenadora do Ambulatório e do Curso de Aperfeiçoamento em Disfagias Neurogênicas da Santa Casa de São Paulo, São Paulo, SP, Brasil. Professora de graduação da UniFMU, São Paulo, SP, Brasil. Mestre em Neurociências pela Universidade Federal de São Paulo/ UNIFESP.

Conflito de interesses: inexistente potencialidades vocais e os recursos dos quais podem se apropriar para terem um melhor desempenho em seu trabalho. Por este motivo, a atuação do fonoaudiólogo e do médico otorrinolaringologista a cantores profissionais, tem sido cada vez mais difundida no país.

Atualmente, é bastante claro que os profissionais da voz dependem de um treinamento vocal específico e direcionado à sua demanda, de forma ainda mais específica, quando se trata de cantores ${ }^{1}$. Sendo assim, é importante que o fonoaudiólogo compreenda melhor as particularidades envolvidas nesse tipo de atuação, para desenvolver um trabalho adequado que beneficie o grupo em questão. Além disso, o fonoaudiólogo é considerado referência de orientação, quando comparado com os diferentes seguimentos de especialistas, que se destinam a orientar pessoas que utilizam a voz profissionalmente ${ }^{2}$. 
No que se refere ao grupo de profissionais da voz cantada, vários estudos nacionais e internacionais têm buscado caracterizá-lo. A maioria das pesquisas tem como foco principal a identificação dos sinais e sintomas vocais e laríngeos mais comuns, investigação de hábitos de saúde vocal e dados da avaliação perceptivo-auditiva e acústica da voz ${ }^{3-6}$.

Alguns hábitos vocais do cantor podem ser incompatíveis com seu bem-estar vocal, danificar os tecidos laríngeos e produzir uma qualidade de voz alterada. Dentre os hábitos prejudiciais está o fumo, álcool, poluição, drogas, medicamentos, alimentação inadequada, vestuário incorreto, além de hábitos do próprio comportamento vocal como pigarrear, tossir e gritar ${ }^{7}$.

Foi realizado um estudo retrospectivo no ambulatório de Otorrinolaringologia da Faculdade de Medicina da USP, com o objetivo de caracterizar profissionais da voz no tocante à procura por atendimento especializado. Os autores observaram que os profissionais que mais procuram por atendimento médico devido a problemas de laringe e voz são os professores, vendedores e cantores, respectivamente ${ }^{8}$. Esse dado é alarmante, uma vez que que problemas vocais podem causar prejuízos profissionais aos indivíduos e interferir na qualidade de vida ${ }^{9,10}$.

Em relação aos hábitos de bem-estar vocal, quando se pensa na distinção entre grupos de profissionais da voz cantada, destacam-se inúmeras diferenças existentes entre cantores populares e líricos. Em geral, cantores líricos são bastante disciplinados no trabalho, visto que têm uma exigência em relação à qualidade vocal, musicalidade, percepção, afinação, timbre e extensão vocal ${ }^{9}$. Assim, observase que, mesmo sem nunca terem tido orientações específicas sobre os hábitos de bem-estar vocal e a utilização da voz profissional, algumas informações são conhecidas pelos cantores líricos. No entanto, estudo recente concluiu que professores de canto lírico ainda têm pouco preparo no que se refere à prevenção de problemas vocais de seus alunos ${ }^{11}$.

No canto popular brasileiro, os ajustes fonatórios se aproximam dos ajustes de fala, e a interpretação é o principal recurso utilizado para a transmissão da emoção. O canto popular desenvolve um estilo próprio e, nesta busca, é frequente a observação de imitações que podem causar abusos vocais ${ }^{12}$. Cantores populares, em geral, têm bem menos requinte vocal e, não raro, apresentam qualidades vocais alteradas. Os diversos sub-estilos dentro desse grupo, como sertanejo, samba, axé e bossa nova geram muitas variações sobre comportamentos e utilização da voz, sem exigirem um grande preparo. Além disso, pesquisas apontam que o cantor popular, na maioria das vezes, desconhece muitos dos cuidados relacionados ao bem-estar vocal e estratégias de conservação da voz ${ }^{12,13}$. Os abusos mais frequentes neste grupo de profissionais são o tabagismo, o etilismo, pouca hidratação, alimentação ou sono inadequados, falta de técnica na utilização da voz cantada com conseqüente tensão na produção do canto, uso excessivo da voz, podendo acontecer em ambientes com fumaça e ruídos. Além disso, muitos cantores estão sujeitos ao estresse, geralmente causado por horários desregrados ou por instabilidade financeira ${ }^{7}$.

Todos os aspectos mencionados acima consideram que muitos cantores populares não têm formação específica em canto e baseiam-se exclusivamente, no dom que eles têm para cantar. Assim, claramente esses cantores apresentam diferentes graus de conhecimento vocal, quando comparados a cantores líricos que, invariavelmente, tiveram muitos anos de estudo e contato com diversos professores e profissionais da área.

Sabe-se que, atualmente, nem todas as informações divulgadas como corretas tanto no meio lírico quanto no popular têm procedência científica. Algumas orientações importantes não são de conhecimento da maioria e, a falta delas, pode fazer diferença em curto ou longo prazo, no que se refere ao desempenho e ao bem-estar vocal. A prática de aquecimento e desaquecimento vocal, por exemplo, tem sua importância descrita em estudos internacionais ${ }^{14,15}$, mas muitas vezes não é de conhecimento nem faz parte da rotina profissional dos cantores.

Recente pesquisa com profissionais da voz cantada constatou que eles referem ter conhecimento sobre a importância de ingerir a água, realizar exercícios de projeção e de aquecimento, evitar gritar ou beber líquidos gelados. O consumo da água foi verificado em todos os cantores, porém os exercícios de desaquecimento não foram mencionados ${ }^{2}$.

Na prática clínica do fonoaudiólogo e do médico otorrinolaringologista tem-se observado que ainda existem alguns mitos divulgados no meio artístico de cantores profissionais e não-profissionais, provavelmente por falta de conhecimento aprofundado deste público sobre temas que envolvam a produção vocal. Portanto, acredita-se que o conhecimento sobre hábitos de bem-estar vocal, oferecido a cantores líricos e populares com formação específica, pode contribuir para nortear o atendimento clínico e terapêutico a partir da promoção de uma orientação específica, individualizada e indicada para o cantor. 
O objetivo do presente trabalho foi comparar hábitos de saúde vocal entre cantores líricos e populares com formação musical específica

\section{MÉTODOS}

Foi realizado um estudo de caráter exploratório descritivo e natureza quantitativa, junto a cantores líricos e populares em formação no Centro de Estudos Tom Jobim/Universidade Livre de Música (ULM), que responderam a um questionário sobre os hábitos de saúde vocal. Foram selecionados aleatoriamente 30 cantores líricos e 30 cantores populares, de ambos os sexos, sendo 25 homens e 35 mulheres. A idade dos cantores variou de 19 a 39 anos (média 27,1).

Vale a pena mencionar que a ULM é uma escola de música profissionalizante bastante reconhecida no país, que oferece formação pública e gratuita de qualidade. Por isso, o processo seletivo é bastante criterioso e exige preparo prévio dos cantores. No período de formação, que pode durar até seis anos em atividades divididas em períodos semestrais, os alunos recebem formação em técnica vocal e percepção vocal por meio de conhecimentos que vão desde a iniciação musical até o aperfeiçoamento desses conteúdos. Os professores da instituição são cantores experientes. Até o momento de realização do estudo, não havia na grade curricular nenhuma disciplina ministrada por fonoaudiólogos ou que envolvessem as questões vocais sob o enfoque da saúde.

Foram incluídos todos os cantores que aceitaram participar voluntariamente do estudo, e excluídos aqueles que haviam, em qualquer momento anterior, recebido orientações profissionais específicas relacionadas à saúde da voz ou que haviam passado por tratamento fonoaudiológico ou otorrinolaringológico devido a problemas vocais.

Inicialmente, o projeto passou por autorização da direção da escola e dos professores de canto lírico, para o consentimento à pesquisa junto aos seus alunos. O questionário aplicado pela pesquisadora foi composto por 13 questões referentes a hábitos externos relacionados ao bem-estar vocal (alimentação, hidratação, tabagismo e drogas recreacionais como maconha e cocaína); dados referentes à demanda vocal do cantor (associação da voz cantada com a voz profissional falada, condições gerais de trabalho e carga horária semanal); conhecimento da população sobre o trabalho fonoaudiológico junto a cantores; utilização de mitos (recursos difundidos popularmente, porém sem comprovação científica de seus benefícios) na tentativa de melhorar a voz diante de quadro disfônico e, finalmente, realização ou não de aquecimento e desaquecimento vocal como parte da rotina da atividade de canto.

Todas as questões eram objetivas e fechadas: 5 questões com alternativas relacionadas a variáveis quantitativas (de copos de água, xícaras de bebida cafeinada, horas de sono/repouso por dia, carga horária de canto semanal e tempo de carreira), 3 questões com alternativas dispostas por meio de escala de Likert (etilismo, prática de aquecimento vocal, pratica de desaquecimento vocal), 3 questões dicotômicas (tabagismo, drogas ilícitas e outra profissão) e 2 questões referente a variáveis qualitativas (como considera o trabalho fonoaudiológico junto a cantores recursos/mitos utilizados na tentativa de melhorar a voz).Com exceção da questão referente aos mitos/recursos saudáveis, em que o cantor poderia assinalar mais de uma alternativa pois poderia ter utilizado mais de um durante a vida, todas as outras permitiam apenas uma possibilidade de resposta.

Todos os participantes da pesquisa assinaram o Termo de Consentimento Livre e Esclarecido regulamentado pela lei $n^{\circ}$ 196/96 do CONEP. A pesquisa foi aprovada pelo Comitê de Ética em Pesquisa da Irmandade da Santa Casa de Misericórdia de São Paulo, sob o número 354/06.

Os dados coletados foram analisados estatisticamente por meio do teste não paramétrico denominado "Igualdade de duas proporções", que compara se a proporção de respostas de duas determinadas variáveis e/ou seus níveis é estatisticamente significante, possibilitando a comparação entre os perfis dos grupos estudados. Foi adotado um nível de significância de $5 \%(p=0,05)$.

\section{RESULTADOS}

A Tabela 1 mostra a comparação do hábito de hidratação entre cantores líricos e populares. Observa-se que não há diferença estatisticamente significante entre os dois grupos, sendo que 12 cantores (40\%), em cada grupo, referiram ingerir de 4 a 8 copos de água por dia. A distribuição de sujeitos que referiram as outras opções (menos de 2 copos, 4 a 8 copos, mais de 8 copos) também foi similar em ambos os grupos, não havendo diferença estatisticamente significante.

Na Tabela 2, é possível observar a comparação do hábito de ingestão de bebidas que contenham cafeína, entre os cantores estudados. A opção mais citada pelos grupos foi a de menos de 2 copos por dia, selecionada por 15 (50\%) cantores líricos e 14 $(46,7 \%)$ populares, respectivamente. Não houve diferença estatisticamente significante entre os grupos. 
Tabela 1 - Comparação da hidratação entre cantores líricos e populares

\begin{tabular}{cccccc}
\hline & \multicolumn{2}{c}{ Líricos } & \multicolumn{2}{c}{ Populares } & \multirow{2}{*}{ p-valor } \\
\cline { 2 - 5 } & $\mathbf{N}$ & $\%$ & $\mathbf{N}$ & $\%$ & \\
\hline Menos de 2 copos & 1 & $3,30 \%$ & 0 & $0,00 \%$ & 0,313 \\
2 a 4 copos & 9 & $30,00 \%$ & 8 & $26,70 \%$ & 0,774 \\
4 a 8 copos & 12 & $40,00 \%$ & 12 & $40,00 \%$ & 1 \\
mais de 8 copos & 8 & $26,70 \%$ & 10 & $33,30 \%$ & 0,573 \\
\hline
\end{tabular}

${ }^{*} \mathrm{p}<0,05 ;$ Teste de Igualdade de duas proporções

Tabela 2 - Comparação da ingestão de bebida cafeinada entre cantores líricos e populares

\begin{tabular}{cccccc}
\hline & \multicolumn{2}{c}{ Líricos } & \multicolumn{2}{c}{ Populares } & \\
\cline { 2 - 5 } & $\mathbf{N}$ & $\%$ & $\mathbf{N}$ & $\%$ & p-valor \\
\hline Menos de 2 copos & 15 & $50,00 \%$ & 14 & $46,70 \%$ & 0,796 \\
2 a 4 copos & 10 & $33,30 \%$ & 12 & $40,00 \%$ & 0,592 \\
4 a 8 copos & 5 & $16,70 \%$ & 3 & $10,00 \%$ & 0,448 \\
mais de 8 copos & 0 & $0,00 \%$ & 1 & $3,30 \%$ & 0,313 \\
\hline
\end{tabular}

${ }^{*} p<0,05$; Teste de Igualdade de duas proporções

A Tabela 3 mostra a comparação da quantidade de horas de sono/repouso por dia entre os grupos, com diferença estatisticamente significante entre eles. Sete $(23,3 \%)$ cantores populares repousam apenas de 2 a 6 horas/dia em comparação a um $(3,3 \%)$ cantor lírico que deu a mesma resposta. Em contrapartida, $10(33,3 \%)$ cantores líricos referiram dormir de 8 a 12 horas/dia, número este, estatisticamente significativamente em relação aos três (10\%) cantores populares que apresentaram a mesma resposta.

$\mathrm{Na}$ Tabela 4, tem-se a comparação entre os hábitos de tabagismo, etilismo e utilização de drogas recreacionais. É possível observar que não há diferença estatisticamente significante entre os grupos para nenhum dos cruzamentos. A maior parte dos cantores, 16 (53,3\%) líricos e 15 (50\%) populares, referiu nunca ingerir bebidas alcoólicas e, $30(100 \%)$ e 28 (93,3\%) participantes da amostra, respectivamente, não fumavam ou faziam uso de outras drogas.

Em relação aos recursos utilizados na tentativa de melhorar a voz diante de um quadro disfônico, $25(83,3 \%)$ cantores líricos, referiram recorrer a recursos considerados como mitos, ou seja, sem comprovação científica (gengibre, gargarejos, pastilhas, chás) contra $18(60 \%)$ cantores populares, com diferença estatisticamente significante entre eles (Tabela 5). A tabela também mostra que foi maior o número de cantores populares $12(40 \%)$, que referiu recorrer somente aos recursos considerados saudáveis (água, maçã, repouso vocal) em comparação aos cinco cantores líricos $(16,7 \%)$, com tendência a diferir de forma estatisticamente significante em relação ao outro grupo.

Dentre os mitos, ou seja, hábitos difundidos culturalmente, porém sem comprovação científica em relação aos seus benefícios ou malefícios,

Tabela 3 - Comparação das horas de repouso/dia entre cantores líricos e populares

\begin{tabular}{cccccc}
\hline & \multicolumn{2}{c}{ Líricos } & \multicolumn{2}{c}{ Populares } & \multirow{2}{*}{ p-valor } \\
\cline { 2 - 5 } & $\mathbf{N}$ & $\%$ & $\mathbf{N}$ & $\%$ & \\
\hline 2 a 6 horas/dia & 1 & $3,30 \%$ & 7 & $23,30 \%$ & $0,023^{*}$ \\
6 a 8 horas/dia & 19 & $63,30 \%$ & 19 & $63,30 \%$ & 1 \\
8 a 12 horas/dia & 10 & $33,30 \%$ & 3 & $10,00 \%$ & $0,028^{*}$ \\
mais de 12 horas/dia & 0 & $0,00 \%$ & 1 & $3,30 \%$ & 0,313 \\
\hline
\end{tabular}

${ }^{*} p<0,05$; Teste de Igualdade de duas proporções 
Tabela 4 - Comparação de tabagismo, etilismo e drogas entre cantores líricos e populares

\begin{tabular}{ccccccc}
\hline & & \multicolumn{2}{c}{ Líricos } & \multicolumn{2}{c}{ Populares } & \multirow{2}{*}{ p-valor } \\
\cline { 3 - 6 } & & $\mathbf{N}$ & $\%$ & $\mathbf{N}$ & $\%$ & \\
\hline \multirow{3}{*}{ Etilismo } & Algumas vezes/semana & 2 & $6,70 \%$ & 1 & $3,30 \%$ & 0,554 \\
& de vez em quando & 12 & $40,00 \%$ & 14 & $46,70 \%$ & 0,602 \\
& Nunca & 16 & $53,30 \%$ & 15 & $50,00 \%$ & 0,796 \\
\hline \multirow{2}{*}{ Tabagismo } & Não & 30 & $100,00 \%$ & 28 & $93,30 \%$ & 0,15 \\
& Sim & 0 & $0,00 \%$ & 2 & $6,70 \%$ & 0,15 \\
\hline \multirow{2}{*}{ Drogas } & Sim (maconha) & 0 & $0,00 \%$ & 2 & $6,70 \%$ & 0,15 \\
& Não & 30 & $100 \%$ & 28 & $93,30 \%$ & 0,554 \\
\hline
\end{tabular}

${ }^{*} p<0,05 ;$ Teste de Igualdade de duas proporções

Tabela 5 - Comparação de recursos utilizados por cantores líricos e populares

\begin{tabular}{cccccc}
\hline & \multicolumn{2}{c}{ Líricos } & \multicolumn{2}{c}{ Populares } & \multirow{2}{*}{ p-valor } \\
\cline { 2 - 5 } & $\mathbf{N}$ & $\%$ & $\mathbf{N}$ & $\%$ & \\
\hline Mitos & 25 & $83,30 \%$ & 18 & $60,00 \%$ & $0,045^{*}$ \\
Saudáveis & 5 & $16,70 \%$ & 12 & $40,00 \%$ & $0,080 \#^{* *}$ \\
\hline
\end{tabular}

${ }^{*} p<0,05$; Teste de Igualdade de duas proporções ** Tendência a diferença estatisticamente significante

os mais referidos por $16(53,3 \%)$ cantores líricos foram gengibre, mel com própolis e pastilhas. Em relação ao grupo de cantores populares, $16(53,3 \%)$ referiram já terem utilizado mel com própolis e 11 $(36,7 \%)$ terem consumido pastilhas e gengibre na tentativa de melhorar a voz.

Em relação ao tempo de carreira com a utilização da voz cantada, não houve diferença estatisticamente significante entre os grupos, sendo que o tempo médio foi similar em ambos (Tabela 6). Quanto à carga horária semanal de atividade de canto, observa-se que cantores populares têm menor carga horária, sendo que 12 (40\%) referem cantar somente de 1 a 5 horas semanais. Pode-se observar também que, quando os cantores foram questionados se têm outra profissão que não seja cantar, a maioria deles, referiu ter outra profissão. Dezenove $(63,3 \%)$ cantores populares referiram utilizar também a voz profissional falada, com diferença estatisticamente significante quando comparados aos cantores líricos 14 (46,7\%).

A Tabela 7 mostra o conhecimento que os cantores têm a respeito da atuação fonoaudiológica junto a este profissional e como a consideram. Observa-se que 27 (97\%) cantores líricos têm conhecimento sobre o assunto contra 19 (63,3\%) cantores populares. Além disso, 21 (70\%) cantores líricos demonstram conhecimento sobre a importância do trabalho fonoaudiológico para o aprimoramento vocal de profissionais da voz e apenas
$13(43,3 \%)$ cantores populares mencionaram tal conhecimento. Houve diferença estatisticamente significante na comparação dos dois grupos em ambas as questões (conhecimento sobre a atuação fonoaudiológica e como a considera).

Finalmente, na Tabela 8 , há dados sobre a prática de aquecimento e desaquecimento vocal na rotina de utilização da voz cantada dos participantes do estudo. Observa-se que $24(80 \%)$ cantores líricos referem "sempre" aquecer a voz antes da atividade profissional e apenas $17(56,7 \%)$ cantores populares, com tendência a diferença estatisticamente significante entre os grupos. Vinte e um $(70 \%)$ cantores populares referiram nunca realizar desaquecimento vocal após a atividade profissional, com diferença estatisticamente significante em relação a 13 (43,3\%) cantores líricos. Um dos cantores populares deixou de responder a questão.

\section{DISCUSSÃO}

O conhecimento e a investigação sobre hábitos de bem-estar vocal de cantores são fundamentais para fonoaudiólogos e otorrinolaringologistas atuarem junto a estes profissionais. Conhecer melhor o paciente proporciona um atendimento mais dirigido e específico, que pode ser, inclusive, fundamental para o processo de intervenção interdisciplinar. O perfil de hábitos alimentares, tabagismo, 
Tabela 6 - Comparação de tempo de carreira, carga horária semanal e outra profissão entre líricos e populares

\begin{tabular}{|c|c|c|c|c|c|c|}
\hline & & \multicolumn{2}{|c|}{ Líricos } & \multicolumn{2}{|c|}{ Populares } & \multirow{2}{*}{ p-valor } \\
\hline & & $\mathbf{N}$ & $\%$ & $\mathbf{N}$ & $\%$ & \\
\hline \multirow{6}{*}{$\begin{array}{l}\text { Tempo de } \\
\text { carreira }^{\star *}\end{array}$} & 0 a 2 anos & 0 & $0,00 \%$ & 1 & $3,30 \%$ & 0,313 \\
\hline & 2 a 5 anos & 5 & $16,70 \%$ & 7 & $23,30 \%$ & 0,519 \\
\hline & 5 a 10 anos & 7 & $23,30 \%$ & 11 & $36,70 \%$ & 0,26 \\
\hline & 10 a 15 anos & 10 & $33,30 \%$ & 6 & $20,00 \%$ & 0,243 \\
\hline & 15 a 20 anos & 4 & $13,30 \%$ & 2 & $6,70 \%$ & 0,389 \\
\hline & mais de 20 anos & 4 & $13,30 \%$ & 3 & $10,00 \%$ & 0,688 \\
\hline \multirow{5}{*}{$\begin{array}{c}\mathrm{C} / \mathrm{H} \text { semanal } \\
\text { canto }^{\star \star \star}\end{array}$} & 1 a 5 horas & 4 & $13,30 \%$ & 12 & $40,00 \%$ & $0,020^{*}$ \\
\hline & 6 a 10 horas & 6 & $20,00 \%$ & 10 & $33,30 \%$ & 0,243 \\
\hline & 11 a 15 horas & 9 & $30,00 \%$ & 3 & $10,00 \%$ & $0,053 \#$ \\
\hline & 16 a 20 horas & 6 & $20,00 \%$ & 4 & $13,30 \%$ & 0,488 \\
\hline & mais de 20 horas & 5 & $16,70 \%$ & 1 & $3,30 \%$ & $0,085 \#$ \\
\hline \multirow{3}{*}{ Outra profissão } & Não & 8 & $26,70 \%$ & 6 & $20,00 \%$ & 0,542 \\
\hline & Sim- CVPF ${ }^{* * * *}$ & 14 & $46,70 \%$ & 19 & $63,30 \%$ & $<0,001^{*}$ \\
\hline & Sim - SVPF ${ }^{\star * \star * *}$ & 8 & $26,70 \%$ & 5 & $16,70 \%$ & 0,313 \\
\hline
\end{tabular}

${ }^{*} p<0,05$; Teste de Igualdade de duas proporções ${ }^{* *}$ considera-se o primeiro mês a partir da idade mencionada - ex: $(2$ a 5 anos $=2$ anos e 1 mês a cinco anos) ${ }^{* * *}$ Carga horária; ${ }^{* * *}$ Com voz profissional falada ${ }^{* * * *}$ Sem voz profissional falada

Tabela 7 - Comparação do conhecimento da atuação fonoaudiológica entre cantores líricos e populares

\begin{tabular}{cccccc}
\hline \multirow{2}{*}{ Como a considera } & \multicolumn{2}{c}{ Líricos } & \multicolumn{2}{c}{ Populares } & \multirow{2}{*}{ p-valor } \\
\cline { 2 - 5 } & $\mathbf{N}$ & $\%$ & $\mathbf{N}$ & $\%$ & \\
\hline PPC & 4 & $13,30 \%$ & 2 & $6,70 \%$ & 0,389 \\
CA $^{* * *}$ & 2 & $6,70 \%$ & 4 & $13,30 \%$ & 0,389 \\
TC $^{* * * *}$ & 21 & $70,00 \%$ & 13 & $43,30 \%$ & $0,037^{*}$ \\
não conhece & 3 & $10,00 \%$ & 11 & $36,70 \%$ & $0,015^{*}$ \\
\hline
\end{tabular}

${ }^{*} p<0,05 ;$ Teste de Igualdade de duas proporções ${ }^{* *}$ parecida com a do professor de canto ${ }^{* *}$ importante para cantores com alterações vocais ${ }^{* * * * i m p o r t a n t e ~ p a r a ~ o ~ a p r i m o r a m e n t o ~ d e ~ t o d o s ~ o s ~ c a n t o r e s ~}$

Tabela 8 - Comparação de hábito de aquecimento e desaquecimento vocal entre cantores líricos e populares

\begin{tabular}{ccccccc}
\hline \multirow{2}{*}{ Aquecimento Vocal } & \multicolumn{3}{c}{ Líricos } & \multicolumn{2}{c}{ Populares } & \multirow{2}{*}{ p-valor } \\
\cline { 2 - 6 } & $\mathbf{N}$ & $\%$ & $\mathbf{N}$ & $\%$ & \\
\hline algumas vezes & 6 & $20,00 \%$ & 12 & $40,00 \%$ & $0,091 \#$ \\
Sempre & 24 & $80,00 \%$ & 17 & $56,70 \%$ & $0,052 \#^{1}$ \\
\hline \multirow{2}{*}{ Desaquecimento vocal } & \multicolumn{2}{c}{ Líricos } & \multicolumn{2}{c}{ Populares } & \multirow{2}{*}{ p-valor } \\
\cline { 2 - 5 } & $\mathbf{N}$ & $\%$ & $\mathbf{N}$ & $\%$ & $0,018^{*}$ \\
\hline algumas vezes & 17 & $56,70 \%$ & 8 & $26,70 \%$ & $0,037^{*}$ \\
\hline Nunca & 13 & $43,30 \%$ & 21 & $70,00 \%$ &
\end{tabular}

${ }^{*} p<0,05 ;$ Teste de Igualdade de duas proporções 
etilismo, utilização de drogas, condições de trabalho relacionadas à carga horária, dentre outros, pode ser característico em determinados grupos e é importante conhecer estas particularidades para direcionar um atendimento individualizado.

Quanto à alimentação e hábitos como a ingestão de água e cafeína, fumo, álcool e drogas recreacionais, cantores líricos e populares comportaram-se de maneira semelhante. Ambos ingeriam menor quantidade de água do que se indica para profissionais da voz, bem como bebida contendo cafeína, e apresentaram baixíssimos índices de etilismo, tabagismo e uso de drogas. Por um lado, ainda pode-se observar pouca preocupação com a hidratação, uma vez que se recomenda, na literatura, a ingestão de pelo menos dois litros de água por dia ${ }^{16}$. Contudo, também é possível perceber a mudança, no que se refere à conscientização de hábitos deletérios como fumo e álcool que, historicamente, fazem parte da cultura musical. Isso demonstra um avanço no que se refere aos cuidados com a saúde geral e, consequentemente, com a voz.

O baixo índice de tabagismo corroborou com os achados de pesquisas recentes envolvendo esse grupo de profissionais ${ }^{4}$. No entanto, os resultados diferenciaram-se do estudo que investigou hábitos refentes ao bem-estar vocal de cantores populares de samba/pagode, que concluiu que muitos têm o hábito de fumar e ingerir grande quantidade de cafeína semanal ${ }^{13}$. A hipótese que se tem em relação a estes dados, é a de que os cantores populares referidos podem não ter formação específica, diferente dos indivíduos participantes da presente pesquisa, que por conta da formação, podem ter maior preparo e conhecimento ao que se refere ao bem-estar vocal. Os resultados evidenciaram cantores populares atentos à saúde e que não estão distantes dos cantores líricos em termos de conhecimento sobre hábitos e saúde vocal, ao contrário do que a literatura há anos descreve ${ }^{7,12}$.

Ainda em relação aos hábitos de natureza externa, em que a voz é influenciada pelas condições de vida do sujeito, cantores populares têm menos horas de descanso ao dia em comparação a cantores líricos. O repouso adequado é fundamental para que os sintomas de fadiga vocal não apareçam e a voz se mantenha em condições saudáveis e usuais ${ }^{16}$. Pode-se relacionar este aspecto de pouco repouso, ao fato de que grande parte dos cantores populares tem outra atividade profissional que exija a utilização da voz falada, o que pode aumentar a carga horária total de trabalho diária e, consequentemente, reduzir a quantidade de horas disponíveis para o descanso. É importante considerar que a associação da voz profissional falada e cantada, poderia gerar mais sintomas de fadiga vocal neste grupo. Porém, o fato de terem poucas horas semanais dedicadas ao canto como mostra a tabela 6, é provável que apresentem menos sintomatologia, o que faz com que recorram menos aos mitos divulgados culturalmente na tentativa de melhorar a voz como mostra a Tabela 5.

Os resultados da presente pesquisa apontam que cantores líricos têm mais conhecimento sobre o trabalho fonoaudiológico e otorrinolaringológico, do que cantores populares. Cantores líricos têm grande exigência do aparelho fonador e ajustes fonatórios muito específicos, passam por vários professores de canto, iniciam suas carreiras muito cedo e, por isso, são mais suscetíveis a desenvolver sintomas de disfonia, sendo então, mais encaminhados a profissionais da saúde. Acredita-se que cantores populares não conheçam bem o trabalho fonoaudiológico e otorrinolaringológico a profissionais, pelo fato de não necessitarem de grandes ajustes laríngeos e não terem grande exigência à qualidade vocal, uma vez que muitas vozes alteradas fazem sucesso e são aceitas pelo público.

Quanto à diversidade de recursos utilizados na tentativa de melhorar a voz, cantores líricos relatam mais o uso de recursos considerados mitos, ou seja, recursos divulgados culturalmente porém sem comprovação científica quanto a seus benefícios ou malefícios. É importante considerar que são os cantores populares que geralmente são descritos na literatura como grandes usuários destes mitos/ recursos populares, difundidas ao longo dos anos, como benéficos à voz $7,12,13$. Na presente pesquisa, pelo contrário, foi maior o número de cantores populares que referiram apenas utilizar recursos saudáveis, como a ingestão de água e maçã e repouso vocal, o que também evidencia um processo de tomada de consciência por parte deste grupo que possui formação musical específica. Embora na ULM não haja disciplinas ministradas por fonoaudiólogos e com enfoque na saúde, os próprios professores de canto da escola, com muitos anos de experiência profissional, repassam aos alunos algumas informações das quais se apropriaram em algum momento anterior (palestras, cursos, etc.).

A literatura apresenta programas de aquecimento vocal, com o objetivo de preservação e aumento de resistência da voz, bem como técnicas de desaquecimento, para que haja o retorno ao padrão habitual de fala, após o uso profissional da voz ${ }^{14,15}$. Ainda assim, a pesquisa mostrou que cantores líricos, em sua maioria, realizam aquecimento vocal sempre, mas não realizam frequentemente o desaquecimento. Os cantores populares, mesmo com formação musical específica, ou seja, apropriação de técnica vocal, aulas relacionadas à percepção da voz no canto e orientações em geral 
transmitidas por professores durante vários anos de formação profissionalizante, dividem-se quanto ao aquecimento sempre e apenas algumas vezes, e não têm o hábito de desaquecer a voz. Interessante pensar que tem havido uma maior conscientização destes profissionais em relação ao bem-estar vocal, uma vez que muitos aquecem a voz antes de cantar, mas que ainda há grande desinformação quanto ao desaquecimento, talvez por não se considerar o canto como atividade muscular de alto custo energético.

Novos estudos sobre o trabalho fonoaudiológico e otorrinolarigológico com cantores líricos e populares devem ser realizados, a fim que se conheça cada vez mais o perfil desses profissionais e, a partir daí, a atuaçào aconteça de maneira assertiva e adequada junto a esse grupo de profissionais.

\section{CONCLUSÃO}

Em relação à comparação de hábitos relacionados ao bem-estar vocal e uso profissional da voz entre cantores líricos e populares com formação musical específica, pode-se concluir que:
- Cantores líricos e populares têm hábitos semeIhantes quanto à alimentação e hábitos deletérios à saúde vocal como tabagismo, etilismo e drogas recreacionais.

- Cantores populares têm menos horas de sono/ repouso ao dia e diferenciam-se de líricos por terem, em sua maioria, outro trabalho com a utilização da voz profissional falada.

- A carga horária semanal com a utilização da voz cantada é maior em cantores líricos que também referem maior utilização de recursos considerados mitos, ou seja, recursos difundidos culturalmente porém sem comprovação científica quanto aos seus benefícios ou malefícios, na tentativa de melhorar a voz diante de quadro disfônico.

- Cantores líricos possuem maior conhecimento sobre a atuação junto aos cantores.

- A prática de aquecimento vocal é mais freqüente em cantores líricos do que em cantores populares.

- O desaquecimento vocal ainda não faz parte da rotina de trabalho tanto de cantores líricos quanto de cantores populares.

\begin{abstract}
Purpose: to compare vocal welfare habits of lyric and popular singers. Methods: it is a descriptive exploratory work, with the participation of 30 lyrical singers and 30 popular singers. All answered a questionnaire with 13 objective questions about vocal habits and use of professional voice. Data were statistically analyzed Results: popular singers have similar feeding habits as lyrical singers: smoking, alcohol and recreational drug use. Popular singers have fewer hours of sleep/rest along the day, which is a statistically significant difference. This group also differed from the lyrical singers because they have, in most cases, another work, with professional use of spoken voice. there was also a statistically significant increased workload on the use of singing voice in lyric singers, as well as the increased use of resources considering myths to improve the voice. Popular singers know less about the work of speech language pathologists with voice professionals. Lyrical singers warm up the voice with greater frequency over the popular singers, although this second group has demonstrated that this habit has been acquired. Both groups do not systematically slow down their voice, after the professional activity. Conclusion: popular and lyrical singers have some similar habits on the vocal health and they are different mainly due to the weekly to singing workload, using myths to improve voice, knowledge about the speech language pathologist work and voice warming-up practice.
\end{abstract}

KEYWORDS: Voice; Voice Diseases; Habits; Music 


\section{REFERÊNCIAS}

1. Schneider SL, Sataloff RT. Voice therapy for the professional voice. Otolaryngol Clin North Am. 2007 Oct; 40(5):1133-49.

2. Ueda KH, Santos LZ, Oliveira IB. 25 anos de cuidados com a voz profissional: avaliando ações. Rev. CEFAC. 2008; 10(4):557-65.

3. Penteado RZ, Silva CB, Pereira PFA. Aspectos de religiosidade na saúde vocal de cantores de grupos de louvor. Rev. CEFAC. 2008; 10(3):359-68. 4. Ferreira LP, Santos JG, Lima MFB. Sintoma vocal e sua provável causa: levantamento de dados em uma população. Rev. CEFAC. 2009; 11(1):110-8.

5. Zampieri AS, Behlau M, Brasil OC. Análise de cantores de baile em estilo de canto popular e lírico: perceptivo-auditiva, acústica e da configuração laríngea. Rev. Bras. Otorrinolaringol. 2002; 68(3):378-86.

6. Rehder MIBC, Behlau M. Análise vocal perceptivoauditiva e acústica, falada e cantada de regentes de coral. Pró-Fono. 2008; 20(3):195-200.

7. Behlau M, Madazio G, Rehder MI, Azevedo R, Ferreira AE. Voz profissional: Aspectos Gerais da Atuação Fonoaudiológica. In: Behlau MS, organizador. Voz: o livro do especialista. Vol. 2. São Paulo: Revinter; 2005. p.287-367.

8. Fortes FSG, Imamura R, Tsuji DH, Sennes LU. Perfil dos profissionais da voz com queixas vocais atendidos em um centro terciário de saúde. Rev Bras Otorrinolaringol. 2007; 73(1):27-31.

9. Behlau M, Hogikyan ND, Gasparini G. Quality of life and voice: study of a Brazilian population using the voice-related quality of life measure. Folia Phoniatr Logop. 2007; 59(6):286-96.

10. Spina AL, Maunsell R, Sândalo K, Gusmão $R$, Crespo A. Correlação da qualidade de vida e voz com atividade profissional. Rev. Bras. Otorrinolaringol. 2009; 75(2):275-9.

11. Quintela AS, Leite ICG, Daniel RJ. Práticas de aquecimento e desaquecimento vocal de cantores líricos. HU Rev. 2008; 34(1):41-6.

12. Andrada e Silva MA, Costa HO. Voz cantada: evolução, avaliação e terapia fonoaudiológica. São Paulo: Lovise; 1998.

13. Rosa PP, Goulart BNG, Costa EF, Capp E. Levantamento da saúde vocal de uma amostra de cantores de pagode do município de Porto Alegre. Rev. Pró-Fono. 2000; 12(2):87-91.

14. Leite GCA, Assumpção R, Campiotto AR, Silva MAA. O canto nas igrejas: o estudo do uso vocal dos coralistas e não coralistas. Dist Comun. 2004; 16(2):229-39.

15. Amim O, Amim N, Michaeli O. Evaluating the influence of warmup on singing voice quality using acoustic measures. J Voice. 2005; 19(2):252-60.

16. Behlau M, Pontes P. Higiene vocal: cuidando da voz. Rio de Janeiro: Revinter; 2008.

DOI: 10.1590/S1516-18462010005000118

RECEBIDO EM: 15/01/2010

ACEITO EM: 09/04/2010

Endereço para correspondência:

Ana Paula Dassie Leite

Rua André Filipak, 160 - Casa 08

Irati - PR

CEP: 84500-000

E-mail: pauladassie@ hotmail.com 